\title{
Erratum to: A Case of Classical Galactosemia: Identification and Characterization of 3 Distinct Mutations in Galactose-1-Phosphate Uridyl Transferase (GALT) Gene in a Single Family
}

\author{
Ramandeep Singh • Gurjit Kaur • Babu R. Thapa • \\ Rajendra Prasad $\cdot$ Ketan Kulkarni
}

Published online: 10 June 2011

(C) Dr. K C Chaudhuri Foundation 2011

\section{Erratum to: Indian J Pediatr}

$$
\text { DOI 10.1007/s12098-010-0348-y }
$$

The original version of this article unfortunately contained a mistake.

An author has been unintentionally omitted from the authors' list.

Ketan Kulkarni is one of the authors of this article.

The online version of the original article can be found at http://dx.doi.org/ 10.1007/s12098-010-0348-y.

R. Singh $\cdot$ R. Prasad $(\bowtie)$

Department of Biochemistry, Postgraduate Institute of Medical

Education and Research (PGIMER),

Chandigarh 160012, India

e-mail: fateh1977@yahoo.com

G. Kaur

Department of Physiology,

Government Medical College and Hospital,

Sector-32,

Chandigarh 160032, India

B. R. Thapa

Division of Pediatric Gastroenterology,

Postgraduate Institute of Medical Education and Research,

Chandigarh 160012, India

K. Kulkarni

Department of Pediatrics,

Postgraduate Institute of Medical Education and Research (PGIMER),

Sector 12 ,

Chandigarh, India 